\title{
To the question of the importance of self- organization and self-development in professional pedagogical activity
}

\author{
Irina Rasskazova*, and Natalia Savina \\ Omsk State Pedagogical University, Tukhachevskogo Quay, 14, 644099 Omsk, Russia
}

\begin{abstract}
The article clarifies the importance of self-organization and self-development for the professional activity of a teacher in the context of the fourth industrial revolution from the standpoint of competence-based and analytical approaches. The reasonableness of the general formulation of a single "Self-organization and self-development" competence in the Russian Federation Federal State Educational Standards of Higher Education is shown. The article describes the empirical study results of the peculiarities of understanding by pedagogical university students separately the competences of self-organization and self-development, as important factors of their general professional expertise. The novelty of the research is based on the identification of motivational, cognitive, and activity components. It was revealed that the highest generalized mean values were obtained for the cognitive and motivational components of the future teachers' ideas about professional self-development, selforganization and the achievement of professional expertise. The lowest mean values were obtained for the action-oriented component. The obtained results of empirical research can be used in the development of training courses, aimed at increasing the level of students' competences in this area.
\end{abstract}

\section{Introduction}

In the modern dynamic information world, a person needs constant self-development and self-organization in order to meet the requirements of the time, successfully cope with new tasks, quickly adapt to new situations, and be professionally successful. The report of the World Economic Forum "The Future of Jobs", 2020, notes among the skills required by professionals such skills as self-management, flexibility and active learning [1]. "We no longer have the opportunity to remain disorganized. In the XXIst century, being organized becomes a survival skill ...", notes J. Morgenstern [2, p. 21]. The professional education system should contribute to the development of these competences in future teachers. Since in the future a teacher contributes to the formation and development of these competences in their students. It should be noted that a teacher, whose competences are not formed, is unlikely to do this successfully. In the current Federal State Educational.

\footnotetext{
*Corresponding author: nvsavina2015@mail.ru
} 
Standards of Higher Education in Russia (FSES HE), 2018, the universal competences that are consistent with the key competences (skills) or soft skills [3] were added. Selforganization and self-development are represented there by one general competence. This correlates with the research of M.I. Bolotova and I.Iu. Spasskaia: “... the mechanism of professional development and self-development appears as a specific self-organization by the future specialists of their personal educational and developmental space, in which they act as subjects of professional formation and self-development" [4]. Also with the position of A.A. Ushakov on self-organization as a basic conceptual fractal of self-development [5]. The formation and development of the competences of future teachers, along with external factors (features of the educational institution, social environment, life situations), will be influenced by internal factors (understanding of their importance, high level of motivation, development activities). The role of internal subjective factors in solving the problems of professional and pedagogical activity, especially in a situation of the need for rapid changes in the profession, which is typical for the modern education system, is emphasized by such scientists as V.D. Shadrikov, M.I. Diachenko, L.A. Kandybovich etc.

The purpose of the article is to clarify the importance of the self-organization and selfdevelopment competences as part of the professional teacher expertise, as well as to conduct an empirical study and analysis of the features of various components of the future teachers' conceptions about this: cognitive, motivational and action-oriented.

\section{Materials and methods}

In this article, we did not sought to summarize the various formulations of the competences of self-organization and self-development, or to justify one as more correct one. Our theoretical research is based on the ideas of competence-based and analytical approaches in education, therefore, as a working definition, we will take a generalized formulation from the Federal State Educational Standard of Higher Education for bachelor's and master's degrees. This is a group of "Self-organization and self-development" competences: ability to manage one's time, build and implement a trajectory of self-development based on the principles of education throughout life, determine and implement the priorities of one's own activities and ways to improve them based on self-evaluation [3]. However, to further conduct an empirical research, we believe that we should separate self-organization and self-development, in order to determine their ratio to general professional expertise more accurately. Let us explain the meaning of the "Self-organization" competence. The term "self-organizing system" is associated with the name of the English cybernetist W.R. Ashby (1947). The self-organization problems in various fields of science (Physics, Physiology, Philosophy, Mathematics, Psychology, etc.) have been actively discussed since the second half of the XXth century. Because of the all-encompassing nature of the complexity science, there is an abundance of self-organization definitions. [6]. In general, self-organization is the ability of a system to change its structure to maintain stability. Selforganization is a general concept that is used to explain orderliness [7]. With regard to social systems, the self-organization of a person is considered as their ability to manage their activities and personal development. This can be seen in determination, activism, validity of motivation, planning of one's activities, independence, quickness of decisionmaking and taking responsibility for these decisions. At different times, the problem of individual's self-organization was studied by N.V. Kuzmina, N.S. Kopeina, M.A. Vorobeva, A.V. Kirillova, A.D. Ishkov, S. Karver, M.F. Shaier, R.Kh. Iung, D. Anzola, P. Barbrook-Johnson, D.I. Kano, H. Foerster, etc. Pedagogical activity is characterized by a complex content, the presence of various types, tough deadlines. All this is accompanied by a strong nervous tension due to the high moral responsibility [8]. Hence, we can see the growing role of individual's self-organization and the activity of a modern teacher. 
The second competence, self-development, has always been relevant for the teacher. However, in the context of the fourth industrial revolution (K. Shvab), the pace of this process is accelerating. Based on the definition mentioned above (FSES HE), we understand self-development as an active independent process of professional expertise improvement. Periods of professional training, retraining, advanced training are shortened, and they run in parallel with each other and with the process of professional activity. "The window of opportunities for retraining and advanced training of workers has become shorter in the context of the new limited labor market" [1]. Today, professional selfdevelopment is a permanent process. The Atlas of New Professions, developed in Skolkovo, Russian Federation [9], shows the constant emergence of new professions, including in the field of education: the educational platform coordinator, startups mentor, educational trajectories developer, project training organizer and others. All this means a trend that was once outlined by the American futurologist E. Toffler - learn, unlearn and relearn. The requirements for the quality and speed of the teacher's self-development are also increasing due to the fact that modern students are often more flexible and learn about innovations faster than their teachers.

In the empirical part of the research, we study the peculiarities of pedagogical university students' understanding of the separated self-organization and self-development competences, as important factors of their general professional expertise. The existing students' concepts about this will largely determine - to increase or to decrease the motivation for mastering the necessary knowledge, to carry out activities for increasing their level of development. This aspect of professional development presupposes an active, subjective position of the students, implying a conscious attitude to various areas of their own lives. We cannot disagree that "... knowledge about the value aspects of a university student's professional training will help to avoid, localize or eliminate problems in the real educational process" [10]. To study the future teachers' concepts, we have identified components - motivational, cognitive, action-oriented [11], based on the structure of innovative activity (V.A. Slastenin, L.S. Podymova). Cognitive - concepts about their significance and the level of their own development; motivational - evaluating the level of desire (motivation) to achieve professional excellence, expertise, and be able to selforganize; action-oriented - evaluating the level of real actions performed, aimed at their development and improvement. The novelty and relevance of the study is associated with revealing the specifics of these components. The practical significance of empirical research is in the fact that understanding students' concepts about professional selforganization, self-development and professional competence can be the basis for building work, aimed at developing the necessary competences in this area in pedagogical universities for future teachers. Participation in the study will allow the students to actualize and understand their own concepts about these aspects of their own lives, related to professional development. Realize the existing problems and start looking for ways to solve them. The results of the study will be presented and analyzed by that logic (February 2021). The 3rd year students of the Primary Education program of Omsk State Pedagogical University $(n=26)$ took part in it. Age of the study participants: 20 years old. Scientific research method used: questionnaire. The respondents were asked to anonymously evaluate the level of their concepts on a 10-point scale, where 1 is the minimum level, and 10 is the maximum level, using the questionnaire developed by us with closed and open questions. The mean values were calculated for a group of subjects.

\section{Results}

The main result of the theoretical analysis is to clarify the importance of the competence of self-organization and self-development in the teacher's professional activity, its impact on 
the general professional expertise. Self-organization and self-development should be understood as interrelated processes, where self-organization is one of the tools for selfdevelopment. Self-organization allows to prioritize, plan and motivate oneself in relation to professional activities. Teacher's self-development is a permanent process of improving professional expertise based on the principles of lifelong education. In today's unstable and changing conditions, self-development, and as a result, the required level of professional expertise, is impossible without self-organization. Therefore, we can talk about a generalized group of competences.

We present the empirical research results, starting with the mean values for the cognitive component of students' concepts. We referred the certain questions to the cognitive component, by which the students evaluated: 1) the level of their own selfdevelopment; 2) the level of their own self-organization; 3) their level in achieving professional expertise; 4) understanding the importance of professional self-development in their life; 5) understanding the importance of professional expertise in their life; 6) understanding the importance of self-organization in their life; 7) understanding the importance of self-organization in their life in achieving professional expertise. The mean values of students' assessments on these issues are presented in Table 1.

Table 1. Mean values of the cognitive component significance

\begin{tabular}{|l|l|l|l|l|l|l|l|}
\hline Questions numbers & 1 & 2 & 3 & 4 & 5 & 6 & 7 \\
\hline Mean values & 7.3 & 7.3 & 7 & 9 & 8.8 & 9.2 & 9 \\
\hline
\end{tabular}

Similar mean values were obtained (the differences are only 0.3 points) based on the results of answering the questions related to assessing the level of their own selfdevelopment, self-organization and professional competence (questions 1, 2, 3). They range from 7 to 7.3 points. The total mean value for all three questions was 7.2 points. If we conditionally assign the mean values from 10 to 8 points to the high level, 7-4 - to the average and 3-1 - to the low, then these values refer to the upper border of the average level. The distribution of individual values by levels was as following: 8 people for questions 1 and 2, and 10 people for question 3 evaluated their level as high, which was $30.8 \%$ for the first two questions, and $38.5 \%$ for the third. The average level prevails, which was $69.2 \%$ and $61.5 \%$ on the first two questions.

These results indicate that students evaluate their level of professional expertise and competences related to the self-development and self-organization abilities quite highly. It can be assumed that these results are associated with a fairly high self-esteem and successful educational activity of almost all students of this course during two and a half years of study at the university. Undoubtedly, successful educational activity influences self-esteem development. However, at the same time, students also have a certain amount of self-objectivity and self-criticism. At the same time, when students evaluated the significance of all the studied indicators in their own life, much higher results were obtained (from 8.8 up to 9.2 points). They are all attributed to the high level. The total mean value for all 4 questions was 9 points, which is 1.8 points higher than the students' own evaluation of these characteristics development level. The highest mean value (9.2 points) was obtained for question 6 - understanding the importance of self-organization in one's life. Only $2(7.6 \%)$ students' answers were attributed to the average level. Whereas the 5 students' answers to the 4th question (11.4\%), 8 students' answers to the 5 th question $(15.2 \%)$ and 4 students' answers to the 7 th question (7.6\%) were attributed to this level. This is probably due to the understanding that the successful performance of life tasks is impossible without planning and diligence. Their own twenty-year life experience convinced them of this fact. Undoubtedly, this result is positive: the overwhelming majority of students understand how important competence, self-development and self-organization for their successful professional self-realization are. 
The motivational component of the students' concepts was studied using three questions, aimed at evaluating the level of their own motivation (desire) to develop professional expertise and the following competences: 8) competence achieving; 9) selfdevelopment in professional formation; 10) self-organization in professional formation. For all three questions, the same mean values were obtained -8 points. This value is attributed to the lower boundary of the high level. This indicates that students have a fairly high level of motivation for developing expertise and studied competences. Still, this level is 1.2 points lower than understanding the significance of their development.

The action-related component of the concepts was also studied using three questions, by which students evaluated the level of their activity, the actual actions performed, aimed at: 11) achieving professional expertise; 12) professional self-development; 13) selforganization. Mean values are presented in Table 2.

Table 2. Mean values of the action-related component significance

\begin{tabular}{|l|l|l|l|}
\hline Questions numbers & 11 & 12 & 13 \\
\hline Mean values & 7.1 & 6.6 & 6.6 \\
\hline
\end{tabular}

For questions 12 and 13, the same mean values were obtained -6.6 points, which is slightly lower (by 0.5 points) than the values for question 11 . They are all attributed to the upper boundary of the average level. The total value for 3 questions was 6.8 . This is 1.2 points lower than the total value for the motivational component and 0.4 points lower than the values for evaluating their own level of expertise and competences development, and 2.2 points lower than the values for understanding the importance of their professional activity development.

The total mean values of the students' concepts components significance about the formation of their professional expertise and specific competences are presented in Figure 1.

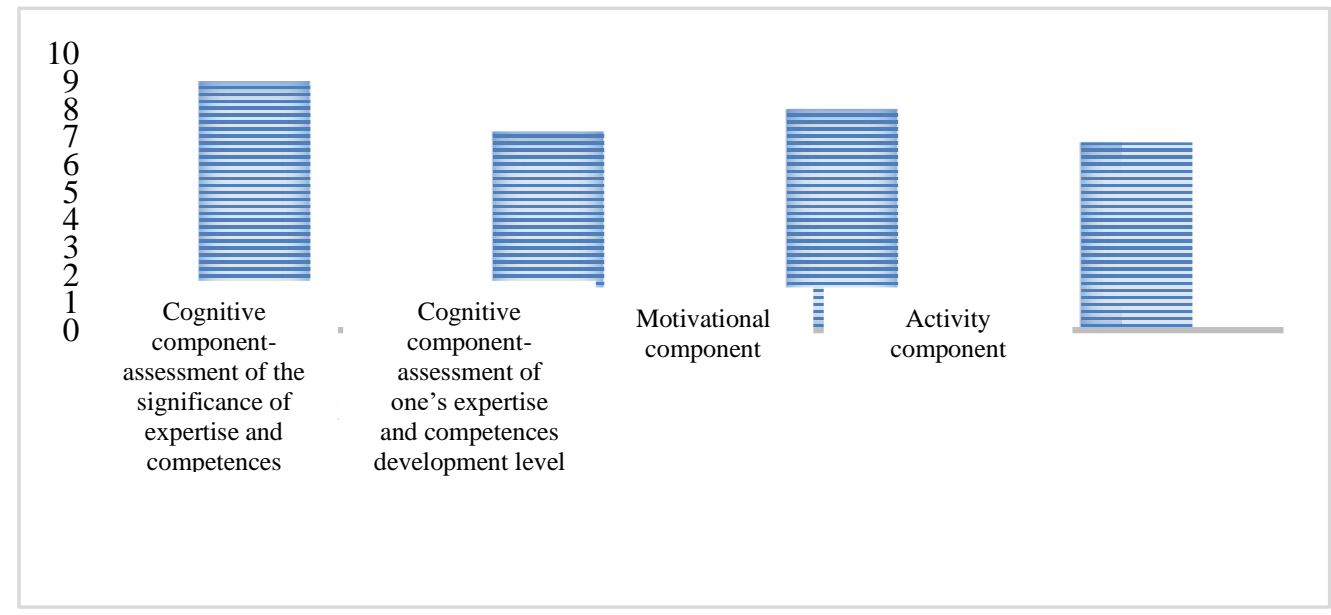

Fig. 1. Total mean values of the students' concepts components significance about the formation of their professional expertise and specific competences.

A high level of students' understanding of the importance of professional expertise and self-organization and self-development competences, as well as motivation to develop them can be considered as a positive result. Evaluation of their development means a certain perspective, a direction of development. Students understand how important these qualities are and they want to develop them. However, at the same time, in reality, they do much less, than needed. And that is a problem. From our point of view, taking into account the influence of internal (personality traits) and external (environmental and situational) factors on human behavior and development, the following explanation of this result is possible. Personal: insufficient formation of strong-willed processes, inability to allocate time 
effectively; struggle of values and motives, when, in addition to educational and professional activities, there are other important areas of life. External, objective: lack of time associated with a busy university schedule; lack of job competition in the system of education, presence of a large number of job vacancies. Understanding of the fact that a person with virtually any level of professional expertise with a vocational training diploma will be hired, does not stimulate professional development.

\section{Conclusions}

An analysis of approaches to defining the self-organization and self-development competences shows their connection as a tool and a result, as well as a necessary basis for the formation of professional expertise. The increasing complexity of professional pedagogical activity requires a specialist's high-quality development of the generalized group of "Self-organization and self-development" competences.

According to the results of the empirical research, the highest total mean values were obtained for the cognitive and motivational components of the future teachers concepts about professional self-development, self-organization and the achievement of professional expertise. The lowest mean values were obtained for the action-oriented component. The obtained results of the empirical research can be used or taken into account in the development of training courses, aimed at increasing the level of students' competences in this area. For example, there is a "Problems of professional self-organization and selfdevelopment" course at the Omsk State Pedagogical University. Also, this information can be useful for teachers who, understanding importance of the competences, pay serious attention to the students' competences development through university disciplines and interaction with the students. From our point of view, based on the results obtained and the problems identified, in order to increase the level of these important indicators of the professional development of students, it is necessary to pay more attention to the following issues: axiological; semantic; related to helping students in understanding their own professional development; understanding the impact on this process of various personal and social factors, including the university education features; operational; instrumental; associated with learning to build a time perspective for life, both long-term and short-term; to form the ability to allocate time in accordance with the goals and objectives, taking into account the understanding of the importance of creating a harmonious life balance, in which an individual manages to develop and realize different sides of their self in various areas of personal and professional life. Which, of course, is an important factor in the psychological individual's well-being.

\section{References}

1. The Future of Jobs 2020, https://www.weforum.org/

2. J. Morgenstern, Organizing from the Inside Out (2006)

3. Federal State Educational Standards of Higher Education of undergraduate and graduate programs (2018) http://fgosvo.ru/

4. M.I. Bolotova, I.Yu. Spasskaia, Scientific Digital Journal: Modern problems of science and education, 6 (2016) https://science-education.ru

5. A.A. Ushakov, The world of science. Pedagogy and psychology, 2 (2020) https://mirnauki.com

6. D. Anzola, P. Barbrook-Johnson, D.I. Kano, Comput Math Organ Theory, 23, 221 (2017) 
7. R.Kh. Yung, International Encyclopedia of Civil Society (2010) https://doi.org

8. N.V. Savina, E.V. Lopanova, Time management in education (2020)

9. Atlas of Emerging Jobs (2020) http://atlas100.ru

10. Yo.N. Ganieva, A.V. Kiryiakova, E.V. Lopanova, V.G. Gladkikh, A.N. Sazonova, G.V. Mitina, O.B. Shirokikh, Humanities \& Social Sciences Reviews, 7(4), 1255 (2019)

11. L.S. Podymova, Psychological and pedagogical innovation: personal aspect (2012) 